\title{
PRÁCTICAS POPULARES, FICCIONES NARRATIVAS Y REFLEXIÓN FILOSÓFICA EN AMÉRICA LATINA
}

\author{
Jaime Rubio Angulo* \\ doi:10.11144/Javeriana.uph32-65.ppfn
}

\begin{abstract}
RESUMEN
Este artículo plantea la necesidad de interpretar la filosofía latinoamericana a partir de su experiencia narrativa. Para ello, hay que aprehender el estilo reflexivo de América Latina como una manera de configuración cultural y como un trabajo del símbolo propios. Asimismo, se impone el identificar la reflexión filosófica latinoamericana como una táctica de pensamiento que responde y resiste a la estrategia del poder hegemónico europeo. Finalmente, se sostiene que no es posible pensar la identidad latinoamericana sin practicar una ética política que transponga por analogía las figuras narradas con las figuras de la historia a la situación de demanda de justicia en la que nos encontramos.
\end{abstract}

Palabras clave: relato; filosofía latinoamericana; ficción; narración; símbolo

* En el decenio de la muerte de Jaime E. Rubio Angulo (1949-2005), profesor de las facultades de Filosofía y Comunicación de la Pontificia Universidad Javeriana, y de la facultad de Artes de la Universidad Nacional de Colombia, el equipo editorial de Universitas Philosophica, con la aquiescencia de la Revista estudios de filosofía, de la Universidad de Antioquía, rinde un homenaje a su legado filosófico con la reimpresión de este artículo, tomado de: Rubio Angulo, J. (1990). Prácticas populares, ficciones narrativas y reflexión filosófica en América Latina. Revista estudios de filosofía, 2, pp. 99-106.

Para citar este artículo: Rubio Angulo, J. (2015). Prácticas populares, ficciones narrativas y reflexión filosófica en América Latina. Universitas Philosophica, 32(65), pp. 275-288, ISSN 01205323, ISSN en línea: 2346-2426, doi:10.11144/ Javeriana.uph32-65.ppfn 


\title{
POPULAR PRACTICES, NARRATIVE FIC- TIONS AND PHILOSOPHICAL REFLECTION IN LATIN AMERICA
}

\author{
Jaime Rubio Angulo
}

\begin{abstract}
This article addresses the need to interpret Latin American philosophy from its narrative experience. To do this, we must grasp the reflective style of Latin America as a way of cultural configuration and as a symbol work of its own. In addition, to identify Latin American philosophy as a tactic to respond and resist the strategy of the European hegemonic power is essential. Finally, it is argued it is not possible to think of Latin American identity without practicing a political ethic which transposes the figures of narratives with the figures of history to the justice demand situation in which we find ourselves.
\end{abstract}

Key words: story; Latin American Philosophy; fiction; narration; symbol 
Filosofía LATINOAMERiCANA es para mí una expresión que describe un estilo de reflexión, esto es, la manera como el filósofo responde a las exigencias de su situación con los elementos que tiene 'a la mano' comprendiendo, es decir, creando proyectos. Permítanme aclarar lo que entiendo por estilo.

El estilo, las "maneras de hacer", constituyen un repertorio colectivo que podemos localizar en las formas de "utilizar" el lenguaje, "escribir" textos, "demarcar" y "administrar" los espacios, etc. Estos procedimientos de muy diverso origen pueden cruzarse en campos de actividades individuales como "los actores anónimos que cruzan la escena que lleva el nombre de un supuesto autor" (De Certeau, 1987, p. 64).

Estas prácticas, especificadas por los estilos, son más estables que sus campos de aplicación; no se pueden identificar con el lugar donde se ejercen. Las prácticas no son totalizantes, no hacen parte de sistemas coherentes. Es posible identificar los estilos de las operaciones intelectuales unidas a las formas de ejercicio de poder.

Podemos "identificar el estilo táctico del procedimiento jurídico que transforma lo episódico en escena de la ley, el estilo estratégico de la enunciación profesoral o clerical que transforma lo particular en caso de la ideología general; el estilo escrito de la manipulación textual que hace de la distancia un principio de autoridad" (De Certeau, 1987, p. 64). Nosotros mismos constituimos un campo de experimentación y elucidación de las prácticas de poder que funcionan como prácticas de intelectuales; pensamos que al denunciarlas podemos inventar formas de pensar diferentes.

Entendemos la reflexión como el acto de reapropiación de sí, que el sujeto realiza, mediante la interpretación de las obras en las cuales expresa su deseo de ser y su esfuerzo por existir. ¿Por qué llamar a este proceso una reapropiación? Porque el "yo" del "yo pienso" no se comprende a sí mismo como sujeto de las operaciones de conocimiento, volición, estimación, etc. $\mathrm{O}$, para decirlo más radicalmente, no hay coincidencia entre ser y conocer. El sujeto primero se produce y luego se conoce. En consecuencia, no hay comprensión de sí que no esté mediatizada por los signos, los símbolos y los textos. La comprensión de sí coincide con la interpretación de los términos mediadores. 
Este estilo reflexivo no escapa a una cierta paradoja: se trata de la paradoja de 'la distancia de la proximidad y la proximidad de la distancia'. Percibimos la diversidad cada vez más cerca. La apertura hacia las demás culturas es hoy la condición de nuestra adhesión a un centro de perspectiva. La tensión entre lo 'propio' y 'lo extraño' forma parte de la interpretación a través de la cual intentamos aplicarnos a nosotros mismo el sentido singular de una tradición concreta, en este caso, de la tradición filosófica.

Esta tensión entre lo propio y lo extraño no implica ninguna visión englobante, ningún 'sobrevuelo'; por el contrario, este esfuerzo por comprender es un esfuerzo situado y es esa comprensión de nuestra situación la que anima el estilo reflexivo que podemos llamar 'filosofía latinoamericana'. Pienso que la 'filosofía latinoamericana’ es un momento hermenéutico de la apropiación-aplicación de la tradición. "Aplicación no quiere decir aplicación ulterior de la generalidad dada, comprendida primera en sí misma, a un caso concreto; ella es más bien la primera verdadera comprensión de la generalidad que cada texto dado viene a ser para nosotros. La comprensión es una forma de efecto, y se sabe a sí misma como efectual" (Gadamer, 1995, p. 414).

Quiero ahora enfrentar el problema de la 'configuración cultural' de nuestros pueblos desde el punto de vista de la reflexión hermenéutica. En efecto, como dice Paul Ricœur: "un continente en trabajo, como América Latina, es el testigo privilegiado de eso que se puede llamar el trabajo del símbolo” (Ricœur et al., 1979, p. 23).

\section{Culturas populares: culturas excluidas}

A partir del Renacimiento se da un proceso de reflexión-exclusión de la cultura popular (ordinaria) que se había ido gestando durante la Edad Media. ¿Cuál es el interés histórico que anima esta represión, cómo se realiza y qué justifica?

Sin duda, el proceso fundamental es el de la centralización política sobre el que se superpone otro, más antiguo: el de la homogenización religiosa. Muchembled ha señalado, para el caso de Francia, cómo el Estado-Nación es incompatible con una sociedad polisegmentaria cuyas relaciones y equilibrios internos están regidos por complejos rituales religiosos y festivos. Las viejas relaciones sociales son reemplazadas por nuevas formas masivas de un modelo de racionalidad, de 
una nueva forma de civilización que lentamente disciplina las culturas populares. En esta nueva civilización se ha de abrogar el derecho de las culturas ordinarias.

Se trata de un lento proceso que tiene como finalidad minar las fronteras interiores de esas culturas: sus dialectos, sus fiestas, sus ritos, sus ritmos y sus tiempos, y que va a producir la cultura nacional (Martin, 1989). Paradójicamente, las culturas ordinarias se convierten en objeto de estudio justo cuando se les niega el derecho a vivir. Como dice Michel de Certeau: "Es cuando el pueblo ya no puede hablar, que los estudiosos se interesan por su idioma” (De Certeau, 1974, p. 55).

A las culturas ordinarias les ocurre lo mismo que a las brujas o a los endemoniados: los elementos de su lenguaje son los que la sociedad les impone y solo esos; su acto de elocución consiste en viajar por el código social. Buena parte de los análisis que la cultura "oficial" hace de la cultura ordinaria o popular se reduce a ideologizar ciertos lugares y grupos, afirmando que allí la marginalidad se encuentra bien e integrando, así, un lugar previamente identificado dentro de un orden social que no cambia. Los procedimientos y la multiplicidad de mecanismos presentes en estos procesos de exclusión-represión van desde la desinstitucionalización de sus relaciones sociales hasta el control de la sexualidad; desde la desvalorización del cuerpo hasta la inoculación de un sentimiento de inferioridad (De Certeau, 1975).

A mediados del siglo XviII, la cultura popular va a sufrir una aventura singular: se la va a considerar a la vez como tradicional y como rebelde. Observada desde el prejuicio ilustrado, la cultura popular va a ser vista como el ámbito de lo mítico, de la ignorancia y de la superstición. En una palabra, es el ámbito del "prejuicio". Ciertamente, como dice Gadamer, hay un prejuicio sobre el prejuicio y, por esta razón, la mentalidad ilustrada es incapaz de comprender el contenido y la intencionalidad histórica de la economía cultural de la multitud ${ }^{1}$, que se irá desmoronando lentamente y será reemplazada por la economía política de mercado libre.

La cultura popular, la cultura ordinaria, apunta entonces hacia una cultura de clase: para el caso mexicano a comienzos del siglo xx, C. Monsivais encuentra

1 "El motín de subsistencias en la Inglaterra del siglo XVIII fue una forma muy compleja de acción popular directa, disciplinada y con claros objetivos. (...) Estaba basado en una idea tradicional de las normas y obligaciones sociales, de las funciones económicas propias de los distintos sectores dentro de la comunidad que, tomadas en conjunto, puede decirse que constituían la economía 'moral' de los pobres" (Thompson, 1979, p. 66). 
en el teatro de revolución, en el music-hall y en el albur, en el lenguaje obsceno y en la grosería mímica - "las malas palabras son gramática esencial de clase" (Monsivais, 1978, p. 101) - la presencia de esa cultura a partir de la cual "el pueblo se solidariza consigo mismo (...) y va configurando su nombre para acceder a una visibilidad que le confiere un espacio social" (Monsivais, 1978, p. 101).

Una nueva complicación se añadirá a todas a las interiores: la cultura popular comienza a ser llamada cultura de masas. "Es decir, en el momento histórico en el cual la cultura popular apunta a su constitución como cultura de clase, esa misma cultura va a ser minada desde dentro, hecha imposible y transformada en cultura de masa" (Barbero, 1983, p. 61), en singular. La cultura de masa no aparece de golpe; por el contrario, es resultado de un método que tiene como finalidad buscar el consenso que racionaliza, que cubre-oculta las diferencias entre las clases. Según R. Hoggart, cuando la aceptación del orden social por parte de las clases populares se apoya sobre "valores de tolerancia, de solidaridad y gusto por la vida que hace cincuenta años expresaba la voluntad de las clases populares por transformar sus condiciones de vida y conquistar su dignidad (el libro de Hoggart es de 1957), entonces lo popular se identifica con lo masivo" (Hoggart, citado en Martin, 1987, p. 88).

Pero dentro de ese espacio delimitado estratégicamente y, a pesar de la represión secular, se siguen dando las tácticas de la cultura popular. Entendemos por estrategia, "el cálculo de las relaciones de fuerza que llegan a ser posibles a partir del momento en que un sujeto de querer o de poder es aislable de "un medio ambiente". Postula un lugar susceptible de ser circunscrito como propio, y sirve como base para la gestión de sus relaciones con una exterioridad distinta" (De Certeau, 1990, p. XLIX). La modernidad se ha constituido sobre este modelo estratégico ${ }^{2}$.

Por el contrario, la táctica es un "cálculo" que no se puede hacer sobre un lugar propio, ni sobre una frontera. La táctica tiene como lugar el "lugar del otro". Se insinúa fragmentariamente, sin totalizarla ni tenerla a distancia, es una victoria del tiempo sobre el espacio. La táctica depende del tiempo para "coger al vuelo" las oportunidades. Lo que "gana" no se capitaliza. Es un juego constante con los

2 Véase, también: De Certeau, 1979. 
acontecimientos para crear las "ocasiones". Su síntesis intelectual no tiene como forma un discurso sino la decisión, la acción y la forma de "agarrar la ocasión".

Al denominar tácticas a las prácticas de la cultura popular queremos recuperar lo originario en el plano de la espontaneidad vital; "volver al mundo de la vida" es volver a lo sensible que no deja de alimentar nuestra reflexión, a la Naturaleza (como diría Spinoza) que experimentamos y de la cual sacamos a la vez la fuerza y la lucidez para las empresas humanas. Las tácticas de la cultura popular no expresan otra cosa que el deseo de justicia que es, al mismo tiempo, deseo de que se haga justicia (Dufrenne, 1980).

\section{El relato como teoría de las prácticas}

Quiero recuperar una tesis de Michel de Certeau, que encuentro especialmente fecunda para pensar el problema que nos ocupa. La

literatura -dice de Certeau- es el discurso teórico de los procesos históricos. Ella crea el no-lugar en donde las operaciones efectivas de una sociedad acceden a una formalización [...] será necesario verla como lo que durante mucho tiempo ha sido la matemática para las ciencias exactas: un discurso lógico de la historia, la ficción que la hace pensable". (De Certeau, 1987, p. 119)

Así pues, una teoría del relato es indisociable de cualquier teoría de las prácticas.

Encontramos un magnífico ejemplo de esta teoría de las prácticas en Don Quijote. En efecto, Don Quijote es, a comienzos del siglo XVII, para la hidalguía española, "la figura que organiza las prácticas de una sociedad, pero se convierte en la escena donde se produce su inversión crítica. No es más que el lugar de su otro, una máscara" (De Certeau, 1987, p. 131). Se trata de la literatura como ejercicio del deseo conforme con la tradición de la lectio.

Creo que debemos reconocer la legitimidad teórica del relato. No podemos seguir considerándolo como un "residuo" que no podemos evacuar, sino como una forma necesaria de la teoría de las prácticas.

Recientemente, Paul Ricœur, en su trabajo Temps et récit, ha mostrado las relaciones entre los procesos de configuración narrativa y la redescripción de la temporalidad y la acción humana. Ricœur compone su teoría de la Triple Mímesis como una mediación entre el análisis fenomenológico del tiempo y la composición narrativa. El filósofo se aplica al análisis de las variaciones imaginativas, de 
las figuras de la experiencia temporal, que solo la ficción puede explotar en el tiempo mortal y el tiempo monumental. Su estudio está jalonado por las obras de Virginia Woolf, Thomas Mann y Marcel Proust.

Por mi parte, he intentado aplicar el modelo hermenéutico de Ricœur a Cien años de soledad. No se trata ahora de repetir el análisis, por lo demás exigente, solo quiero llamar la atención sobre algunos puntos especialmente interesantes. Frente a todos los críticos que han canonizado la idea de un tiempo circular como negación de la historia, opongo la idea del presente como tiempo absoluto del "esto está sucediendo". El "instante" es el protagonista temporal de la novela, pero no será un instante medido por el reloj (ien Macondo no hay relojes!). Es el instante como "decir ahora", como "hacer presente". Con razón había escrito Carlos Fuentes que Macondo es la "sede del tiempo, consagración de los tiempos, lugar de cita de la memoria y el deseo, presente donde todo puede recomenzar" (Fuentes, 1969, pp. 118-122).

El presente se duplica en el instante de lectura dentro de la novela. "Cien años" como el escenario de la subversión, como realización del deseo, como lectio. Aureliano, el "lector", última de las transformaciones simbólicas en la novela, es una figura ética en un sentido muy cercano a la concepción de J. Lacan ${ }^{3}$. Ética del deseo, deseo de ética doblemente cifrado en el "instante de la lectura", "instante paradójico": decisivo e indeciso. Es como el umbral donde se superponen lo que nos es dado conocer y lo desconocido de las decisiones por tomar: las opciones de la libertad. "Momento de lectura" en que somos alterados con todo lo que esta palabra significa, instante que nos envía a nosotros mismos, instante que está como suspendido, "instante que dura cien años" hasta que nosotros comprometamos nuestra propia temporalidad en una verdadera existencia concreta. En esta ficción el tiempo es cualificado de otra manera. No es solamente el tiempo de la presencia; es, también, el tiempo de la posibilidad.

La reflexión anterior nos obliga a introducir una categoría de Nietzsche en la que encontramos el equivalente a la metáfora narrativa de García Márquez: se trata de la fuerza del presente. Lo que Nietzsche ha logrado ver es la "interrupción" que

Véase: Lacan, 1988. 
opera el presente frente a la fascinación de la historiografía monumental, frente a la abstracción del pasado.

Nietzsche, en su Segunda consideración intempestiva, consagra la que podemos llamar la "virtud" del presente: "Es en virtud solamente de la fuerza suprema del presente como usted tiene derecho a interpretar el pasado" (Nietzsche, 1964, p. 205): solo la grandeza del hoy es lo que permite refigurar el tiempo. La verdadera historia, dice Nietzsche, es la que permite transformar en una verdad completamente nueva lo que es conocido por todos, y de expresarlo con tanta simplicidad y profundidad que la profundidad haga olvidar la simplicidad y la simplicidad la profundidad.

Para terminar, quiero mostrar algunas posibilidades para la reflexión filosófica que se dejan instruir a partir de las ficciones narrativas. En primer lugar, el tema de la identidad. No es este un problema extraño a la filosofía latinoamericana. Considero que la ficción narrativa nos ofrece instrumentos para repensar este problema. Frente a la identidad como mismidad (Idem - same), el relato construye una especie de identidad dinámica correspondiente a la intriga, una identidad que Ricœur ha llamado narrativa y que corresponde al "Ipse" latino, al "Self" inglés, al "Selbst" alemán. Esta "Identidad narrativa" del personaje sería correlativa a la historia narrada. Instruidos por esta noción de "Identidad narrativa" podemos repensar el problema de la configuración de nuestros pueblos. La configuración cultural no sería otra cosa que su "ipseidad", su "sí-mismo" instruido por las obras de la cultura que ella se aplica a sí misma; la comunidad construye su carácter recibiendo relatos que llegan a ser su historia efectiva.

No hay comunidad sin un proyecto durable, y es función de la política hacer duradera la comunidad. ¿Cómo podría una comunidad tener un proyecto si no se apoya sobre la acumulación de historias narradas, es decir, sin una memoria? Frente a esto, debemos ser conscientes de las limitaciones de la "Identidad narrativa". Esta es solo uno de los hilos de este complejo entramado.

La configuración cultural no se puede separar de las dimensiones normativas, evaluativas y prescriptivas que el texto vehicula, y de las que nos apropiamos o rechazamos por medio del acto de lectura. Leer es aceptar o rechazar una visión del mundo que jamás es éticamente neutra, que induce implícita o explícitamente a una nueva evaluación del mundo y del lector. 
La ética es otro de los temas nucleares de la relación filosófica latinoamericana. Pienso que nuestros relatos nos ofrecen suficientes figuras éticas para construir esa fenomenología del deseo de justicia, que es, al mismo tiempo, deseo de que se haga justicia.

Hay que justificar este nombre que damos al deseo, puesto que no se trata tan solo de recuperar las ideas de justicia moral o jurídica. Lo que está en juego es un nuevo imaginario social. El deseo de justicia se despierta por la experiencia cotidiana de injusticia, y esta experiencia de injusticia sufrida en carne propia no está conceptualizada, como tampoco lo está la justicia, la cual no esta conceptualizada pero sí está-siendo narrada.

Llegados a este punto aparece otro problema: en este contexto, ¿cuál es el lugar de 'el Otro'?

Según la función narrativa, el Otro tiene dos papeles: es aquel que cuenta y enseña, o es aquel que escucha lo que se cuenta para apropiarse de la historia y expresarse por ella. $\mathrm{Y}$, aunque podemos preguntarnos: ¿contar una historia no es una nueva forma de imponer al otro un orden que aliena, no es someter al otro a los esquemas de comprensión del narrador?, la pregunta que se impone es si este lenguaje narrativo no es el que se necesita para que pueda expresarse lo totalmente Otro.

El relato vive, se adapta a las circunstancias en donde la historia es contada. El contar lo reconstruye a su manera, y el oyente lo escucha según su propia experiencia y su propia escucha; el relato solo puede vivir bajo la forma de una narración escuchada, de una re-narración. Solo el relato vivo restituye la intriga, pero la hace revivir de manera tal que el sentido se desplaza para adaptarse a cada individuo, a la experiencia propia de su vida.

El orden del relato narrado siempre tiene en cuenta la pluralidad de los hombres. La ética exige una narración para hacerse entender: sin una narración viva el interés por el Otro tiende a volverse un misticismo mudo. Practicar la ética política es vivir en analogía con las figuras de una historia, más que conformarse a las normas que son abstracciones que expresan esas prácticas. Vivir en analogía con una figura narrada no es ni calco ni identificación, es la transposición de una o de muchas figuras ejemplares a la situación en donde uno se encuentra. 
La lucha por la identidad narrativa de un pueblo puede amenazar el orden social, mientras que el establecimiento del orden puede amenazar o reprimir el ejercicio de la identidad. Aquí, la hermenéutica puede ayudar porque no existe orden social sin relatos ni historias que cuenten cómo se estableció, cómo se establecerá y cómo los hombres participarán en esta construcción. No seremos justos con los deseos de nuestros pueblos si no conocemos su identidad narrativa; a su vez, los hombres solo pueden comprenderse aplicándose a sí mismos los mitos e historias de su propia sociedad. Así mismo, no diremos nada de una sociedad mejor y diferente sin presentar su forma narrativa. El relato de acontecimientos posibles que permita pasar de una sociedad a otra se hace indispensable, como también es indispensable el recurso a relatos antiguos para exponer 'la buena vida' a la cual uno aspira.

Una palabra final para exponer mi reconocimiento al maestro Leopoldo Zea. Siempre me había intrigado el uso que el maestro Zea hacía de La tempestad de W. Shakespeare. Esa subversión que se configura en el teatro es, a mi gusto, refigurada por el Dr. Zea en el Discurso de clausura del XVII Congreso Mundial de Filosofía. "Es obvio que este preguntar y este responder sobre nuestra identidad, sobre nuestro ser, sobre nuestra humanidad, ha de ser hecho a partir de nuestra lengua, en la que nos hemos formado y a través de la cual adquiere sentido el mundo, nuestro mundo". La subversión que supone reconocer que podemos hacer filosofía en español es comprable a lo que escribe Carlos Fuentes en Terra Nostra como el "Teatro de la Memoria” en donde intervienen: "Imágenes que integran las posibilidades del pasado, pero también representan todas las oportunidades del futuro, pues sabiendo lo que no fue, sabremos lo que clama por ser" (Fuentes, 1985, p. 565).

\section{Referencias}

Barbero, J.M. (1983). Memoria narrativa e industria cultural. Comunicación y cultura, 10, pp. 59-73.

Barbero, J.M. (1987). De los medios a las mediaciones. Comunicación, cultura y hegemonía. Barcelona: Editorial Gustavo Gili S.A.

De Certeau, M. (1974). La culture au pluriel. Paris: aux Éditions du Seuil.

De Certeau, M. (1975). L'Écriture de la Historie. Paris: Gallimard. 
De Certeau, M. (1979). Pratiques quotidiennes. G. Poujol \& P. Labourie (Eds.), Les cultures populaires (pp. 23-30). Touluse: INEP, E. Privta, Editeur.

De Certeau, M. (1987). Histoire et psychanalyse entre science et fiction. Paris: Gallimard.

De Certeau, M. (2000). La invención de lo cotidiano I. México D.F.: Universidad Iberoamericana.

Dufrenne, M. (1980). Subversión. Perversión. Madrid: Ruedo Ibérico.

Fuentes, C. (1985). Terra Nostra. Barcelona: Seix-Barral.

Gadamer, H-G. ([1960] 1995). Verdad y método. Fundamentos de una bermenéutica filosófica. (Trad. A. Agud de Aparicio). Salamanca: Ediciones Sígueme.

Lacan, J. (1988). La ética del psicoanálisis. El seminario libro 7. Buenos Aires-México D.F.: Paidós.

Monsivais, C. (1978). Notas sobre cultura popular en México. Latin American Perspectives, 5(1), pp. 98-118.

Nietzsche, F. (1964). Considérations inactuelles. Paris: Aubier

Ricœur, P. et al. (1979). El tiempo y las filosofias. Salamanca: Ediciones Sígueme-Unesco.

Thompson, E.P. (1979). Tradición, revuelta y conciencia de clases. Barcelona: Crítica. 